\title{
Talking about Comprehensive Quantitative Assessment System of College Students
}

\author{
Liuchuang Wei ${ }^{1, a,{ }^{*}}$, Ping Wei ${ }^{2}$ \\ ${ }^{1}$ Faculty of Mechanical and Electrical Engineering, Kunming University, Yunnan Kunming 650214, \\ China \\ ${ }^{2}$ Faculty of Architectural Engineering, Kunming University, Yunnan Kunming 650214, China \\ aweiliuchuang@126.com \\ ${ }^{*}$ Corresponding author
}

Keywords: Institutions of higher learning, Comprehensive quantification, Assessment system, Scholarship system.

\begin{abstract}
The evaluation of student scholarships in colleges and universities is an important part of the work of college students. The scientific evaluation of scholarships in colleges and universities is related to the vital interests of each student. It plays an active role in encouraging students to study hard, strive for excellence, and guide the overall development of college students. The implementation of the operational scholarship quantitative assessment model can better reflect the incentive and guiding role of the national implementation of the scholarship system, improve the scholarship system, and promote the development of quality education. This paper analyzes the status quo and existing problems of the evaluation system, and puts forward its own opinions and opinions on the construction of the evaluation system, which provides clues for the reform and practice of the scholarship system for college students.
\end{abstract}

\section{Introduction}

Contemporary human society is experiencing an unprecedented major change. The transformation of society has brought unprecedented challenges to higher education and brought new opportunities to its development. In order to comply with these changes in society, higher education in all countries should adjust their development strategies and strategies accordingly, and some new development trends have emerged. Since the 1970s, with the highly integrated trend of science and technology on the basis of high differentiation, with the acceleration of the frequency of social changes, the trend of higher education in the direction of integration has become increasingly obvious.

Scholarships are a reward for outstanding students from government, universities, social groups and individuals. The purpose is to mobilize students' enthusiasm for learning, build a good learning atmosphere, and cultivate high-quality talents that meet the needs of modern society. In order to meet the needs of the development of colleges and universities and the reform of education, the comprehensive quantitative assessment model formed by universities in China can be expressed as: semester comprehensive scores $=$ moral education score + intellectual education score + sports score + reward (punishment) score.

\section{Significance of quantitative evaluation model of university scholarships}

Through the evaluation of scholarships among college students, colleges and universities guide and promote the comprehensive development of college students in moral, intellectual, physical, aesthetic and labor. At this stage, most universities in China adopt the two-level scholarship evaluation method. The school formulates the school's scholarship evaluation criteria in accordance with the basic principles of the state's management system for scholarships. Based on the relevant school system, each secondary college has formulated some operational scholarship evaluation rules based on its own specific conditions. Each class is selected by class and submitted to the college for review. The academic achievement and comprehensive quality plus component assessment reform in the 
evaluation of college scholarships are scientific and fair, and can be used as a scholarship evaluation model.

The comprehensive evaluation method is the main method used in the quantitative evaluation model of college scholarships. It is an important means to measure the comprehensive performance of students in one semester or one academic year. The evaluation results become an important basis for scholarship evaluation. The comprehensive evaluation method indicators mainly take the students' academic achievement as the main body, and comprehensively refer to the ideological and moral literacy, social activities, ability and quality, and physical quality, and give a comprehensive assessment. The comprehensive quantitative assessment mode discussed in this paper is to comprehensively consider the students' academic performance, ideological and moral literacy, and ability and quality in the last semester or the previous school year, and finally calculate the comprehensive evaluation scores of each student. The comprehensive quantitative model can be expressed as: comprehensive evaluation score $=$ comprehensive learning score + comprehensive quality plus points.

\section{Disadvantages and problems existing in current college students comprehensive evaluation system}

Comprehensive evaluation refers to the development of a series of quantitative indicators and implementation rules for college students' moral, intellectual and physical aspects. It is an important basis and reference for college students' scholarships, three good students' evaluation and graduate employment. However, due to the existence of defects in human beings such as complete quantification, comprehensive evaluation has entered an embarrassing situation of "student rejection, teacher headache".

\subsection{Evaluation system is not perfect and indicators are not reasonable}

Most colleges and universities convert moral education, intellectual education, and sports into three basic indicators. If we analyze this framework system with the current quality education concept, we will find the limitations of this framework system.

\subsubsection{One-sided consideration of academic performance}

At present, the comprehensive evaluation carried out by many universities in China is often limited to academic performance. These colleges use the scores as the criterion for judging the level of students' intellectual education, which obliterates the students' sense of innovation and makes students out of touch with society and lacks social practice ability. This evaluation mode guides students to pursue the balanced development of each homework. Many students neglect the cultivation of comprehensive comprehensive qualities and abilities in order to obtain the high scores of each homework. Although this kind of evaluation affirms the difference in students' knowledge accumulation, intellectual education refers to the students' learning ability and not just academic achievement.

\subsubsection{Institutionalization of reward and punishment standards}

The rewards and punishments are directly added to the above scores and occupy a very important position in the comprehensive evaluation results. For these extra points, students may actively seek to serve as student cadres, and hope that the higher the "student level", the better, because the higher the "level", the higher the score. In order to add points, some students are forced to do things beyond their capabilities. Some students are in poor health, but they are actively participating in blood donation because of the high bonus for unpaid blood donation. This is not a truly comprehensive development of college students, but a "utilitarian" and "hypocritical" college students. This kind of bonus system does not completely reflect the quality of students, and does not have any real meaning for the improvement of students' quality.

\subsection{Evaluation system operation has loopholes}

In most colleges and universities, the assessment mode of "comprehensive assessment score = moral education score + intellectual education score + sports score + reward punishment" is adopted. Moral 
education points are determined through the discussion of counselors, class teachers and student leaders. In order to get a higher moral education score, some students are gangsters among the classmates. Some of the counselors, class teachers, and student cadres who participated in the assessment had a great say, which gave birth to some students' bad behaviors of bribing teachers in various ways. The results of the study are also worthy of convincing, and the results of the moral education are recorded because of the lack of integrity. This makes it easy for students to lose their life values in the pursuit of utilitarian intrigue.

\section{Principles of constructing college students' comprehensive quantitative assessment system}

The purpose of the comprehensive evaluation system for college students is to formulate specific objective evaluation criteria that are both purposeful and regular, based on the party's educational policy and the school's educational goals. In order to change the one-sided and backward evaluation method, we must establish a scientific and reasonable and highly operational quality evaluation system. To establish a scientific comprehensive evaluation system for college students, we should strive to grasp the following principles.

\subsection{Principle of combining quantitative with qualitative evaluation}

The objectives of comprehensive quality evaluation are diverse, and the evaluation methods and evaluation subjects are diverse. The evaluation model is concerned with both the process and the outcome. Therefore, we cannot use the overall uniform evaluation indicators to treat ever-changing evaluation targets, and we cannot rely solely on quantitative evaluation methods. Colleges and universities can learn from the "Evaluation Program for Undergraduate Teaching Work in Higher Industrial Schools" and adopt the "multi-factor state equation" plus "assessment suggestions" in the expression of evaluation.

\subsection{Establishing and improving guarantee mechanism for development of college students' quality}

As a powerful guarantee for the evaluation of college students' quality, the most important thing is that the school should set up the "Quality Evaluation Center for College Students" to strengthen the theoretical research and work coordination of talent training and quality evaluation. In the cultivation of talents, we should take the market as the orientation, explore the training mode of combining production, study and research, cultivate talents that are welcomed by the society, and pay attention to the cultivation of core knowledge, core competence and core quality. The "Quality Evaluation Center for College Students" should be led by the Department of Education and the Youth League Committee, and is responsible for the quality evaluation and evaluation of the students. The "Quality Evaluation Center for College Students" should hold regular meetings to revise the comprehensive evaluation standards for college students in a timely manner, thus forming a strong guarantee mechanism for the coordination of personnel training and quality evaluation.

\subsection{Assessment work should be transparent}

First, the assessment personnel should be produced by the democratic recommendations of each class. Second, the assessment process should continue to be supervised by other students in order to correct problems in the assessment in a timely manner. Third, the evaluation results are disclosed within a certain range. In particular, each student should be added or subtracted to explain the specific reasons.

\subsection{Increase publicity of evaluation program}

Judging from the past assessment work, many problems are caused by the assessment team and students' understanding of the deviation of the program. Therefore, it is necessary to unify students' understanding of the program through propaganda and avoid misunderstanding. In order to facilitate students' understanding and mastery, all classmates should be explained through the class meeting. 


\section{Summary}

The college scholarship system is an important system for guiding and motivating college students. We must constantly apply new ideas and ideas to guide the evaluation of scholarships to meet the demands of college students in the new era, so that the scholarship system can really play an important role. A comprehensive comprehensive quantitative assessment system and a reasonable scholarship system can encourage students to study hard, develop and develop in an all-round way.

\section{Acknowledgment}

This paper has been supported by the scientific research foundation project of Yunnan Provincial Department of Education (2014Y386).

\section{References}

[1] Y. H. Zheng, Research on Problems and Strategies of University Scholarship Evaluation Mechanism, Journal of Fujian Medical University (Social Science Edition), Vol.17, pp. 24-26, 2016.

[2] Z. J. Wang, Exploring Quantitative Evaluation Model of University Scholarships, Journal of Shanxi Datong University (Social Science), Vol.26, pp. 101-103, 2012.

[3] T. Hu, Talking about Reform of Evaluation Model of University Scholarships, Journal of HUBEI Correspondence University, Vol.24, pp. 18-19, 2011.

[4] Q. H. Lin, The Construction of Undergraduate Scholarship and Appraisal System, Higher Education Forum, No.1, pp. 138-140, 2005.

[5] J. Y. Zhang, L. Y. Yan and M. Cao, Research on Multi-index Model in Evaluation of College Scholarships, Journal of Chongqing Technology and Business University, No.2, pp. 125-129, 2010. 